\title{
A comparison of the photosynthesis response to arsenic stress in two Pteris cretica ferns
}

\author{
V. ZEMANOVÁ,**,+ (D), D. PAVLÍKOVÁ*, F. HNILIČKA*** (D), M. PAVLÍK ${ }^{* * *}$, H. ZÁMEČNÍKOVÁ*, \\ and T. HLAVSA ${ }^{\#}$
}

\author{
Department of Agro-Environmental Chemistry and Plant Nutrition, Faculty of Agrobiology, Food and Natural \\ Resources, Czech University of Life Sciences Prague, Kamýcká 129, 16500 Praha 6, Czech Republic* \\ Isotope Laboratory, Institute of Experimental Botany, Academy of Sciences of the Czech Republic, Videňská 1083, \\ 14220 Praha 4, Czech Republic** \\ Department of Botany and Plant Physiology, Faculty of Agrobiology, Food and Natural Resources, Czech \\ University of Life Sciences Prague, Kamýcká 129, 16500 Praha 6, Czech Republic ${ }^{* * *}$ \\ Department of Statistics, Faculty of Economics and Management, Czech University of Life Sciences Prague, \\ Kamýcká 129, 16500 Praha 6, Czech Republic ${ }^{\#}$
}

\begin{abstract}
The present study investigated the effect of arsenic (As) on photosynthesis and other selected physiological parameters in two ferns. The ferns (Pteris cretica 'Albo-lineata' and 'Parkerii') subjected to As doses of 100 and $250 \mathrm{mg} \mathrm{kg}^{-1}$ for three months, showed different As accumulation, which was higher in Albo-lineata. Overall, the obtained results indicated significant differences between studied ferns. The individual effects of As and growing period on all parameters were very variable. However, As doses generally caused a decrease of net photosynthetic rate, stomatal conductance, transpiration rate, maximum quantum yield of PSII, and photosynthetic pigments. The sampling period effect was significant for magnesium content of Parkerii (decrease) and contents of photosynthetic pigments of Albo-lineata (increase) and Parkerii (decrease). Results showed that Parkerii had higher sensitivity to As doses than Albo-lineata, which was also reflected by the higher free glycine content and its increase by As doses.
\end{abstract}

Keywords: chlorophyll; contamination; free amino acid; gas exchange; hyperaccumulator.

\section{Introduction}

Arsenic is a toxic metalloid present at elevated concentrations in soils and water because of anthropogenic and natural inputs to polluted areas (Karimi et al. 2013). Although As is not essential for plant growth, it can be acquired by roots and translocated into leaves in many plant species (Meharg and Hartley-Whitaker 2002), causing interruption

\section{Highlights}

- Ferns show significantly different sensitivity to As doses

- Arsenic doses negatively affect parameters of photosynthesis in studied ferns

- Photosynthetic pigments changes were reflected by As doses and sampling period
Received 4 January 2021

Accepted 15 February 2021

Published online 18 March 2021

${ }^{+}$Corresponding author

e-mail: zemanovav@af.czu.cz

Abbreviations: Alb - Pteris cretica 'Albo-lineata'; As0 - treatment without As supplementation; As100 - treatment with As dose of $100 \mathrm{mg} \mathrm{kg}{ }^{-1}$; As 250 - treatment with As dose of $250 \mathrm{mg} \mathrm{kg}{ }^{-1}$; Car - carotenoids; Chl $_{\mathrm{T}}$ - total content of chlorophyll; DM - dry mass; $E$ - transpiration rate; FM - fresh mass; $\mathrm{F}_{\mathrm{v}} / \mathrm{F}_{\mathrm{m}}$ - maximum quantum yield of PSII photochemistry; Gly - free glycine; $g_{\mathrm{s}}-$ stomatal conductance; Par - Pteris cretica 'Parkerii'; $P_{\mathrm{N}}$ - net photosynthetic rate; $\mathrm{SP}$ - sampling period; TF - translocation factor of As. Acknowledgements: The research was supported by the Czech Science Foundation (grant No. 17-10591S) and the Ministry of Education, Youth, and Sports from European Regional Development Fund-Project 'Centre for the investigation of synthesis and transformation of nutritional substances in the food chain in interaction with potentially harmful substances of anthropogenic origin: comprehensive assessment of soil contamination risks for the quality of agricultural production' (grant No. CZ.02.1.01/0.0/0.0/16_019/0000845). Conflict of interest: The authors declare that they have no conflict of interest. 
of several morphological, physiological, and biochemical processes, including germination, shoot and root growth, depression of photosynthetic rate, and biomass production (Ahsan et al. 2008, Asgher et al. 2021). Arsenic exposure induces reactive oxygen species that cause oxidative stress, which is the main process underlying As toxicity in plants. One of the main As detoxification mechanisms is the reduction of arsenate $-\mathrm{As}^{\mathrm{V}}$ to arsenite $-\mathrm{As}^{\mathrm{III}}$ (Abbas et al. 2018).

However, in several plant species, especially, ferns from the Pteridaceae family, a phenomenon called As hyperaccumulation, which is an extreme form of plant tolerance under As pollution, can be identified (Luongo and $\mathrm{Ma}$ 2005, Claveria et al. 2019). As-hyperaccumulating plants translocate most of the As from the roots to the fronds (Tu et al. 2002). The fronds of As-hyperaccumulators accumulate As and are also involved in the process of photosynthesis, which is crucial to the primary production of plants (Wang et al. 2012). Ideally, according to these authors, the main physiological processes of the plant, such as photosynthesis, respiration, and water and nutrient metabolism, should not be disturbed when hyperaccumulating extremely high As contents in aboveground parts.

Photosynthesis is the main metabolism process in plants, and its course strongly correlates with the stage of plant development (Skoczowski et al. 2020), especially leaf senescence. In plants, photosynthesis occurs in chloroplasts, in which both light and dark reaction of photosynthesis take place (Ashraf and Harris 2013). Thus, chlorophyll (Chl) content is a measurement of photosynthesis. This parameter is a measure of the ability of a plant to convert photosynthetic energy into biomass, or the measurement of the efficiency of a plant to produce biomass (Wang et al. 2016). One of the key issues in the optimisation of photosynthesis for environmental fitness is a plant's ability to maintain and regulate photosynthesis under stress (Allakhverdiev 2020). Chl fluorescence is closely linked to photosynthesis and is an effective parameter for monitoring a plant's response to environmental stress (Ralph and Burchett 1998, Buschmann 2007, Volkova et al. 2009, Yang et al. 2016).

It has been shown that fern species have a lower photosynthetic capacity than that of seed plants (Gago et al. 2013, Nishida et al. 2015) and display a seasonal acclimation of photosynthetic performance to environmental conditions (Paoli and Landi 2013). However, only limited information is available regarding the difference of photosynthetic processes between As-hyperaccumulator and/or As-nonhyperaccumulator ferns when exposed to As stress (Wang et al. 2012). Singh et al. (2006) reported different As effect on photosynthetic pigments in As-hyperaccumulator Pteris vittata compared to As-nonhyperaccumulator P. ensiformis. Results of Wang et al. (2012) showed that Chl fluorescence parameters were not significantly different in the As-nonhyperaccumulators $P$. semipinnata and $P$. ensiformis as well as As-hyperaccumulator $P$. cretica under As treatments, however, decreased by $100 \mathrm{mg}(\mathrm{As}) \mathrm{kg}^{-1}$ in $P$. vittata.
Transpiration rate of $P$. vittata increased at a low As treatment while decreased at high As treatments (Wan et al. 2015). A change of photosynthesis parameters, photosynthetic pigments, and Chl fluorescence by As was shown in young and old fronds of As-hyperaccumulator $P$. cretica 'Albo-lineata' (Zemanová et al. 2020a). Pavlíková et al. (2020) reported a decrease of photosynthesis and Chl fluorescence parameters by As in As-hyperaccumulator $P$. cretica as well as As-nonhyperaccumulator $P$. straminea. According to Wang et al. (2012), it remains unclear how the fronds of As-hyperaccumulators conduct photosynthesis under As stress and maintain important physiological functions. However, their results suggested that the glycolysis pathway (glyceraldehyde-3-phosphate dehydrogenase), which converts glucose to pyruvate, plays an important role in As-hyperaccumulators' photosynthesis under As stress. Additionally, the $\mathrm{C} / \mathrm{N}$ ratio and homeostasis of amino acids, especially glycine, which is an essential substrate for the biosynthesis of cytokinins and 5-aminolevulonic acid, a substrate for Chl, play an important role in photosynthesis (Pavlíková et al. 2020).

This study aimed to investigate the photosynthesis response of two ferns, Pteris cretica 'Albo-lineata' and 'Parkerii' under different As treatments during the growth period. We studied the impact of As accumulation on the net photosynthetic rate, transpiration rate, stomatal conductance, chlorophyll fluorescence, pigments, $\mathrm{Mg}$ and $\mathrm{K}$ content, and free glycine content after different As treatments. We examined the changes in these parameters over time in control variants of two ferns. Our objective was to evaluate the effect of As on the photosynthesis response and related parameters and to verify the phenotypic differences between the studied ferns.

\section{Materials and methods}

Plant material and experimental design: Plants of Pteris cretica L. 'Albo-lineata' (Alb) and 'Parkerii' (Par) at the 10-15-fronds stage were obtained from the commercial garden centre (Tulipa, Prague, Czech Republic). Ferns were planted in 5-L pots (one fern per pot) under greenhouse conditions, i.e., natural photoperiod; day/night temperature of $22-24 / 18^{\circ} \mathrm{C}$; relative humidity of $60 \%$. Each pot contained $5 \mathrm{~kg}$ of haplic chernozem [16 $\pm 1.7 \mathrm{mg}$ (total As) $\mathrm{kg}^{-1}, 0.10 \pm 0.01 \mathrm{mg}$ (water soluble As) $\mathrm{kg}^{-1}$, As extraction efficiency of $20 \%$, total organic carbon of $1.83 \%$, cationexchange capacity of $258 \mathrm{mmol}(+) \mathrm{kg}^{-1}, \mathrm{pH}_{\mathrm{KCl}} 7.1$, bulk density of $2.57 \mathrm{~g} \mathrm{~cm}^{-3}$, sand $26 \%$, silt $72 \%$, and clay $2 \%$ ), which was collected from a nonpolluted area in Suchdol, Prague, Czech Republic (50 $\left.8^{\prime} 8^{\prime \prime} \mathrm{N}, 14^{\circ} 22^{\prime} 43^{\prime \prime} \mathrm{E}\right)$. Soil was supplemented with $0.5 \mathrm{~g}(\mathrm{~N}), 0.16 \mathrm{~g}(\mathrm{P})$, and $0.4 \mathrm{~g}(\mathrm{~K})$ per 1 $\mathrm{kg}$ of soil as $\mathrm{NH}_{4} \mathrm{NO}_{3}$ and $\mathrm{K}_{2} \mathrm{HPO}_{4}$. Ferns were grown in this soil without As supplementation (As0) and with two As doses: $100 \mathrm{mg}(\mathrm{As}) \mathrm{kg}^{-1}$ (soil) (As100) and $250 \mathrm{mg}(\mathrm{As})$ $\mathrm{kg}^{-1}$ (soil) (As250) for three months. Arsenic was added as a solution of $\mathrm{Na}_{2} \mathrm{HAsO}_{4}$ and was thoroughly mixed with the soil; the maturation period of spiked soil was ten days. Each treatment was replicated three times. Fronds of ferns were harvested three times: before planting $\left[1^{\text {st }}\right.$ sampling 
period (SP)], after $30 \mathrm{~d}$ of growth in the pots $\left(2^{\text {nd }} \mathrm{SP}\right)$, and at the end of the experiment ( $\left.3^{\text {rd }} \mathrm{SP}\right)$.

Determination of As, $\mathbf{M g}$, and $\mathbf{K}$ : Fronds and roots were oven-dried to a constant mass for three days at $40^{\circ} \mathrm{C}$. Homogenised material $(0.5 \pm 0.05 \mathrm{~g})$ was digested with a mixture of $\mathrm{HNO}_{3}$ and $\mathrm{H}_{2} \mathrm{O}_{2}(4: 1, \mathrm{v} / \mathrm{v})$ in an Ethos 1 device (MLS GmbH, Leutkirch im Allgäu, Germany). Arsenic and $\mathrm{Mg}$ content were determined using inductively coupled plasma-optical emission spectrometry (ICP-OES; Agilent 720, Agilent Technologies Inc., Torrance, USA). The content of $\mathrm{K}$ was determined using flame atomic absorption spectroscopy (FAAS; VARIAN SpectrAA-280, Mulgrave, Australia). Certified reference material (CRM NIST 1573a Tomato leaves, Analytika ${ }^{\circledR}$, Prague, Czech Republic) was mineralised under the same conditions for quality assurance.

Arsenic translocation factor: The As translocation factor (TF) was calculated as the ratio of As content in the dry fronds to As content in the dry roots.

Pigment contents in the leaves were measured spectrophotometrically with an Evolution 2000 UV-Vis (Thermo Fisher Scientific Inc., Waltham, MA, USA). A vessel-free leaf segment $\left(0.5 \mathrm{~cm}^{2}\right)$ was incubated in the dark in $1 \mathrm{ml}$ of dimethylformamide with shaking for $24 \mathrm{~h}$. The absorbance of the extract was measured at wavelengths 480, 646.8, and $663.8 \mathrm{~nm}$. Absorbance values at $710 \mathrm{~nm}$ were subtracted from these measurements. Pigment contents were calculated as previously described by Zemanová et al. (2020a).

Chl fluorescence: Chl fluorescence $\left(\mathrm{F}_{\mathrm{v}} / \mathrm{F}_{\mathrm{m}}\right)$ was measured using a modulated chlorophyll fluorometer OS1-FL (OptiSciences, ADC BioScientific, Ltd., Hoddesdon, UK) as previously described by Zemanová et al. (2020a).

Frond gas exchange: The net photosynthetic rate $\left(P_{\mathrm{N}}\right.$ $\left.\left[\mu \mathrm{mol}\left(\mathrm{CO}_{2}\right) \mathrm{m}^{-2} \mathrm{~s}^{-1}\right]\right)$, rate of transpiration $\left(E\left[\mathrm{mmol}\left(\mathrm{H}_{2} \mathrm{O}\right)\right.\right.$ $\left.\left.\mathrm{m}^{-2} \mathrm{~s}^{-1}\right]\right)$, and stomatal conductance $\left(g_{\mathrm{s}}\left[\operatorname{mol}\left(\mathrm{H}_{2} \mathrm{O}\right) \mathrm{m}^{-2} \mathrm{~s}^{-1}\right]\right)$ were determined with the portable gas-exchange system LCpro+ (ADC BioScientific Ltd., Hoddesdon, UK) as previously described in Zemanová et al. (2020a).

Free glycine (Gly) was measured using a Hewlett Packard 6890N/5975 MSD gas chromatography-mass spectrometry system (GC-MS; Agilent Technologies Inc., Santa Clara, CA, USA) as previously described by Pavlíková et al. (2020).

Statistical analyses: All results were analysed in the Statistica 12.0 program (StatSoft Inc., Tulsa, OK, USA). Collected data were checked for homogeneity of variance and normality (Levene's and Shapiro-Wilk's tests). Data did not meet assumptions for the use of analysis of variance ( $A N O V A)$ and thus were evaluated by the nonparametric Kruskal-Wallis's test. Significant differences were assessed as the effect of (1) As treatment on parameters in each sampling period of fern, (2) age of fronds on parameters of the control treatment (senescence), and (3) fern cultivar. Correlations were quantified using the Pearson's linear correlation $(r, p \leq 0.05)$.

\section{Results}

Arsenic content and frond biomass: The accumulation of As and its effect on frond biomass of two P. cretica ferns was measured (Table 1). In all cases, a significant difference in the As contents in fronds and roots as well as frond biomass between ferns was observed. $P$. cretica Alb showed a higher As accumulation and frond biomass than that of Par. In both ferns, the As content in fronds and roots increased with increasing the As dose in the soil (Alb: $r=0.82$ and 0.94, respectively; Par: $r=0.93$ and 0.85 , respectively). As shown in Table 1 , the TF data were variable for both ferns in relation to the As dose and duration of exposure. However, the highest TF during growth was calculated at As250, excluding Par in $3^{\text {rd }}$ SP. In Alb ferns, values of TF correlated with the As dose in the soil $(r=0.59)$. The change in frond biomass of ferns is shown in Table 1 . In both ferns, control variants showed an increased frond biomass with SP. In all As doses, the frond biomass of ferns was slightly lower than that in control variants, excluding Par at As100 in $2^{\text {nd }}$ SP, but the difference did not reach a significant level (Table 1).

Frond gas exchange and $\mathrm{Chl}$ fluorescence: The values of $P_{\mathrm{N}}, \mathrm{F}_{\mathrm{v}} / \mathrm{F}_{\mathrm{m}}, g_{\mathrm{s}}$, and $E$ differed between ferns and As doses in the soil (Fig. 1). Although the ferns showed a similar trend in $P_{\mathrm{N}}$ and $\mathrm{F}_{\mathrm{v}} / \mathrm{F}_{\mathrm{m}}$, their values were significantly different, excluding $1^{\text {st }} \mathrm{SP}$ (Fig. $\left.1 A, B\right)$. In all cases, $P_{\mathrm{N}}$ and $\mathrm{F}_{\mathrm{v}} / \mathrm{F}_{\mathrm{m}}$ decreased with increasing the As dose in the soil (Alb: $r=-0.77, r=-0.85$, respectively; and Par: $r=-0.81$, $r=-0.97$, respectively). Compared to Alb, all $P_{\mathrm{N}}$ values of Par were lower (Fig. $1 A$ ). A similar trend was shown for $\mathrm{F}_{\mathrm{v}} / \mathrm{F}_{\mathrm{m}}$ values, excluding control variants (Fig. $1 B$ ). There were no significant differences between SP of Alb in terms of $P_{\mathrm{N}}$ and Par in terms of $\mathrm{F}_{\mathrm{v}} / \mathrm{F}_{\mathrm{m}}$ (Fig. $1 A, B$ ). The effect of SP was shown for $P_{\mathrm{N}}$ in Par (average increase by $1 \%$ ) and for $\mathrm{F}_{\mathrm{v}} / \mathrm{F}_{\mathrm{m}}$ in Alb (average decrease by $5 \%$ ).

The significant difference between Alb and Par ferns in $g_{\mathrm{s}}$ and $E$ was observed in all cases, excluding $g_{\mathrm{s}}$ values of As 250 in the $3^{\text {rd }} \mathrm{SP}$. In Alb ferns, $g_{\mathrm{s}}$ and $E$ showed the same effect as SP and As dose in the soil (Fig. $1 C, D)$. The two parameters had the highest values in the control variant of the $1^{\text {st }} \mathrm{SP}$ and then decreased in the $2^{\text {nd }}$ (by 76 and $74 \%$, respectively) and $3^{\text {rd }} \mathrm{SP}$ (by 70.5 and $65.5 \%$, respectively). Compared with the control, the As 100 dose of Alb in the $2^{\text {nd }}$ SP increased $g_{\mathrm{s}}$ and $E$, however, the As 250 dose decreased $g_{\mathrm{s}}$ and $E$ (Fig. $1 C, D$ ). In Alb of the $3^{\text {rd }} \mathrm{SP}$, both As doses decreased $g_{\mathrm{s}}$ and $E$ in comparison with the control (by 45 and $42 \%$ on average, respectively). The effect of As dose in the soil on $g_{\mathrm{s}}$ and $E$ was confirmed by correlations ( $r$ $=-0.42$ and $r=-0.43$, respectively). In Par ferns, the $g_{\mathrm{s}}$ and $E$ values were lower than that in Alb ferns, excluding the control of the $2^{\text {nd }} \mathrm{SP}$, which reached the highest values (Fig. 1C,D). The significant effect of As dose on $g_{\mathrm{s}}$ and $E$ was confirmed in the $2^{\text {nd }} \mathrm{SP}$, which decreased with the increasing As dose in the soil (by 49.5 and $45 \%$ on average, 


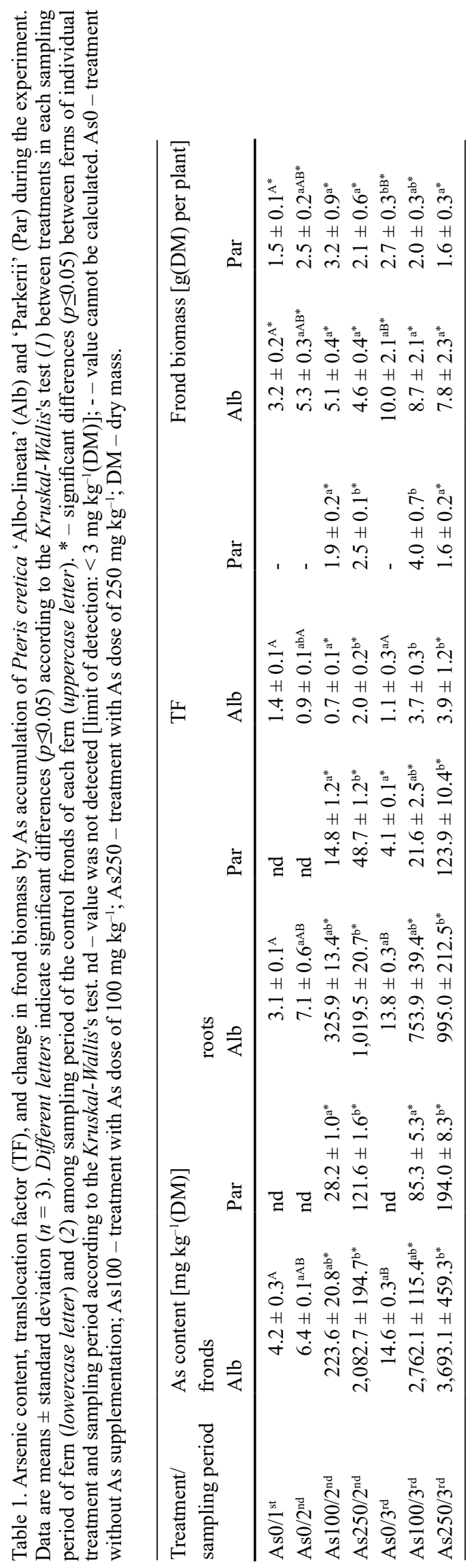

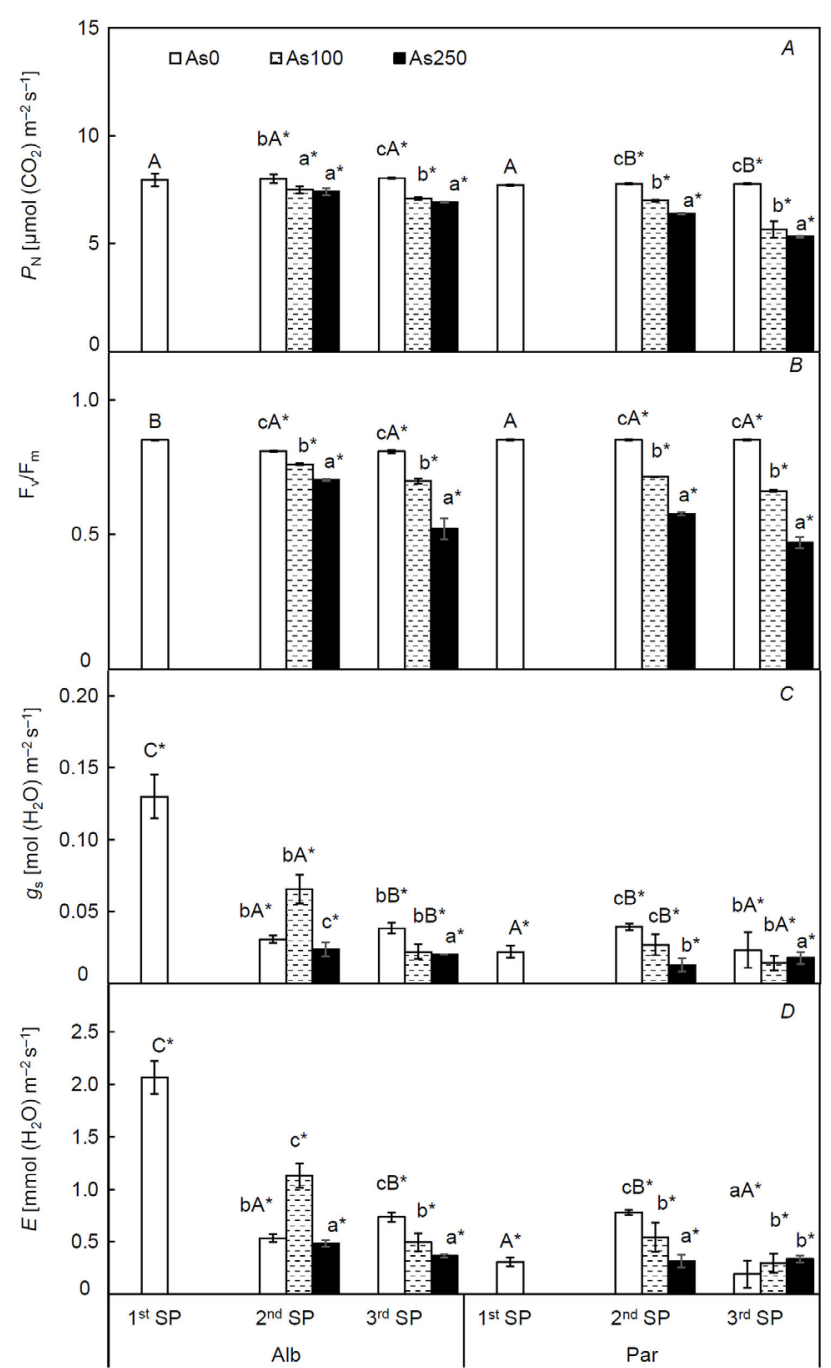

Fig. 1. Effect of As treatments on net photosynthesis $\left(P_{\mathrm{N}}\right)(A)$, chlorophyll fluorescence $\left(\mathrm{F}_{\mathrm{v}} / \mathrm{F}_{\mathrm{m}}\right)(B)$, stomatal conductance $\left(g_{\mathrm{s}}\right)$ $(C)$, and transpiration rate $(E)(D)$ of Pteris cretica 'Albo-lineata' (Alb) and 'Parkerii' (Par) during the experiment. Data are means \pm standard deviation $(n=3)$. Different letters indicate significant differences $(p \leq 0.05)$ according to the Kruskal-Wallis's test (1) between treatments in each sampling period of fern (lowercase letter) and (2) between sampling period of control fronds of each fern (uppercase letter). * - significant differences $(p \leq 0.05)$ between ferns of individual treatment and sampling period according to the Kruskal-Wallis's test. As0 - treatment without As supplementation; As 100 - treatment with As dose of $100 \mathrm{mg}$ $\mathrm{kg}^{-1}$; As250 - treatment with As dose of $250 \mathrm{mg} \mathrm{kg}^{-1}$.

respectively). Conversely, in the $3^{\text {rd }} \mathrm{SP}$ of Par, the effect of As dose was significant only for $g_{\mathrm{s}}$ at As100 (decrease by $37.5 \%$ ) and $E$ at both As doses (increase by $66 \%$ on average). There was a significant correlation between As dose in the soil and $g_{\mathrm{s}}$, as well as $E-r=-0.53$ and $r=-0.25$, respectively.

Pigment content: The effect of As dose in the soil and SP on the $\mathrm{Chl}_{\mathrm{T}}$ and Car contents of Alb and Par ferns is shown 
in Fig. 2. In all cases, a significant difference between ferns in $\mathrm{Chl}_{\mathrm{T}}$ and Car content was observed. A comparison of ferns revealed a higher pigment content in Par fronds than that in Alb fronds, excluding Car in As100 of the $3^{\text {rd }}$ SP (Fig. 2). In Alb fronds, the $\mathrm{Chl}_{\mathrm{T}}$ and Car contents showed the same effect as the SP and As dose in the soil. The $\mathrm{Chl}_{\mathrm{T}}$ and Car content significantly increased by the $3^{\text {rd }} \mathrm{SP}$ (38 and 105\%, respectively) and decreased by As100 of the $2^{\text {nd }}$ SP (47 and 44\%, respectively) and As 250 of the $3^{\text {rd }}$ SP (84 and $86 \%$, respectively). The opposite effect of $\mathrm{SP}$ on $\mathrm{Chl}_{\mathrm{T}}$ and Car contents was observed in Par fronds, which decreased by the $3^{\text {rd }}$ SP (Fig. 2). A significant decrease in the $\mathrm{Chl}_{\mathrm{T}}$ and Car contents by As 250 was shown in Par fronds (by 55 and $60.5 \%$ on average, respectively). In ferns, the relationship between the As dose in the soil and $\mathrm{Chl}_{\mathrm{T}}$ content, as well as Car content, was confirmed by significant correlations (Alb: $r=-0.80, r=-0.72$; Par: $r=-0.75, r=-0.70$; respectively).

Mg and $\mathrm{K}$ contents: Regarding the $\mathrm{Mg}$ and $\mathrm{K}$ contents, $\mathrm{Alb}$ and Par ferns showed significant differences, however, the effect of As dose in the soil and SP was characterised by a high variability and low significant differences (Fig. 3). Compared with the control, in both ferns, the $\mathrm{Mg}$ content was enhanced at As250 dose, but the difference did not reach a significant level (Fig. $3 A$ ). The effect of SP on $\mathrm{Mg}$ content was observed only for Par ferns when $\mathrm{Mg}$ content decreased by the $3^{\text {rd }} \mathrm{SP}$ in comparison to the $1^{\text {st }} \mathrm{SP}$

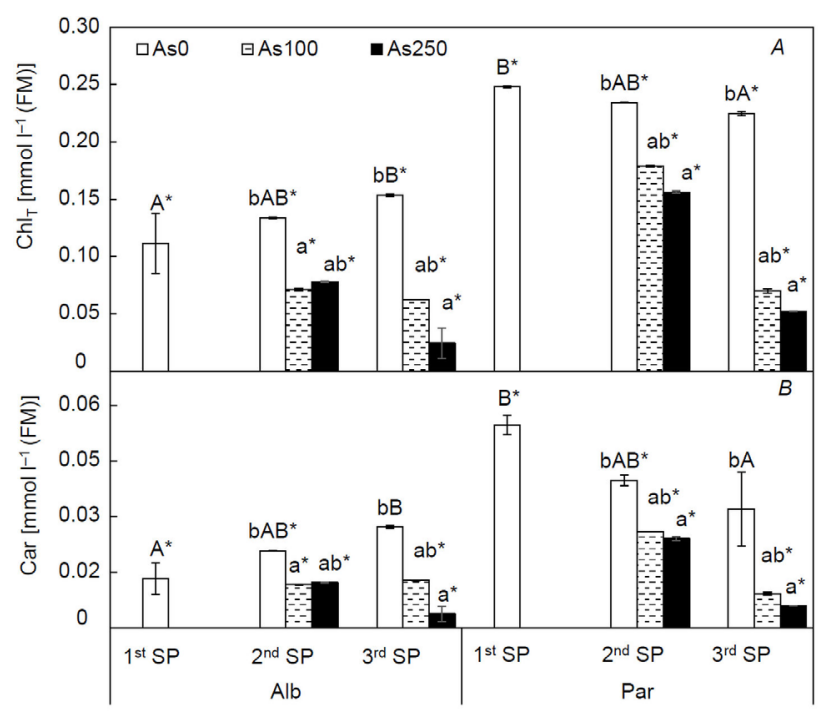

Fig. 2. Effect of As treatments on the total content of chlorophyll $\left(\mathrm{Chl}_{\mathrm{T}}\right)(A)$ and carotenoids (Car) $(B)$ in Pteris cretica 'Albolineata' $(\mathrm{Alb})$ and 'Parkerii' (Par) during the experiment. Data are means \pm standard deviation $(n=3)$. Different letters indicate significant differences $(p \leq 0.05)$ according to the Kruskal-Wallis's test (1) between treatments in each sampling period of fern (lowercase letter) and (2) between sampling period of control fronds of each fern (uppercase letter). * - significant differences $(p \leq 0.05)$ between ferns of individual treatment and sampling period according to the Kruskal-Wallis's test. As0 - treatment without As supplementation; As100 - treatment with As dose of $100 \mathrm{mg} \mathrm{kg}^{-1}$; As 250 - treatment with As dose of $250 \mathrm{mg} \mathrm{kg}^{-1}$; FM - fresh mass. (by $41 \%$ ). $\mathrm{K}$ content was higher in Alb ferns compared to Par ferns, excluding As 250 of the $3^{\text {rd }}$ SP (Fig. $3 B$ ). In both ferns, the $\mathrm{K}$ content decreased in the $2^{\text {nd }} \mathrm{SP}$ (by $38 \%$ on average). Compared with the control, the change in $\mathrm{K}$ content by As dose was significant only in Par for As 250 of the $2^{\text {nd }} \mathrm{SP}$.

Free Gly content: The effect of As dose in the soil and SP on the free Gly content of Alb and Par ferns is shown in Fig. 4. The content of free Gly was higher in Par ferns than that of Alb ferns, excluding the control of the $2^{\text {nd }} S P$. In all cases, a significant difference in the free Gly content between ferns was observed (Fig. 4). The effect of SP in Alb ferns did not reach a significant level. However, compared with the control, a significant increase of free Gly content by As100 (22\%) and As250 (31\%) was observed in Alb of the $3^{\text {rd }}$ and $2^{\text {nd }} \mathrm{SP}$, respectively. In Par ferns, the free Gly content increased by As 250 (122.5\% on average) in comparison with the control, while compared to the $1^{\text {st }} \mathrm{SP}$, it decreased in the $2^{\text {nd }} \mathrm{SP}$ (by $33 \%$ ). In Alb and Par ferns, the relationship between the As dose in the soil and the free Gly content was confirmed by a significant correlations ( $r=0.76$ and $r=0.89$, respectively).

\section{Discussion}

Arsenic accumulation by $P$. cretica is well documented (Meharg 2003, Luongo and Ma 2005, Fayiga and Ma 2005, Wang et al. 2007, Eze and Harvey 2018, Pavlíková

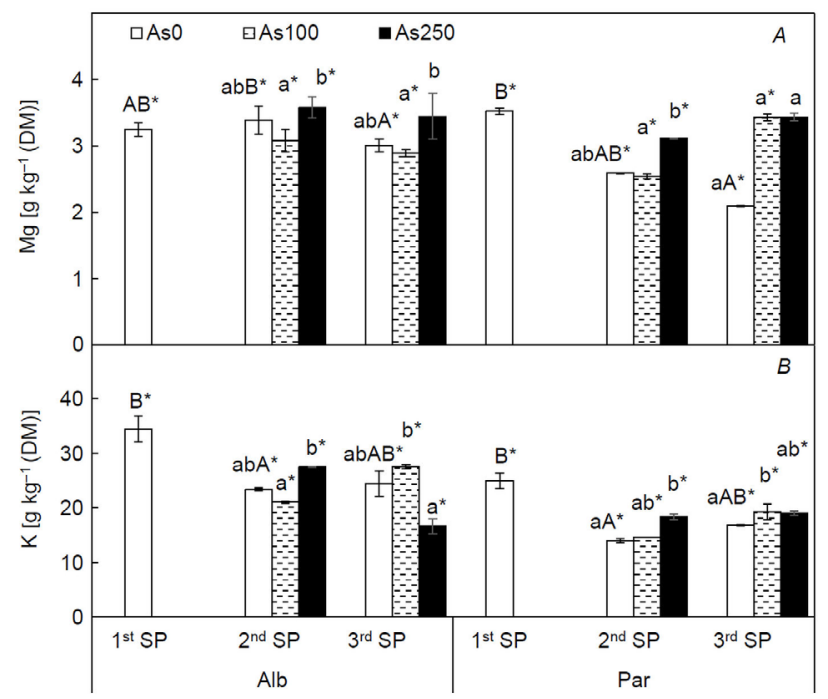

Fig. 3. Effect of As treatments on $\mathrm{Mg}(A)$ and $\mathrm{K}(B)$ content of Pteris cretica 'Albo-lineata' (Alb) and 'Parkerii' (Par) during the experiment. Data are means \pm standard deviation $(n=3)$. Different letters indicate significant differences $(p \leq 0.05)$ according to the Kruskal-Wallis's test (1) between treatments in each sampling period of fern (lowercase letter) and (2) between sampling period of control fronds of each fern (uppercase letter). * - significant differences $(p \leq 0.05)$ between ferns of individual treatment and sampling period according to the Kruskal-Wallis's test. As0 treatment without As supplementation; As100 - treatment with As dose of $100 \mathrm{mg} \mathrm{kg}^{-1}$; As250 - treatment with As dose of $250 \mathrm{mg} \mathrm{kg}^{-1}$; DM - dry mass. 


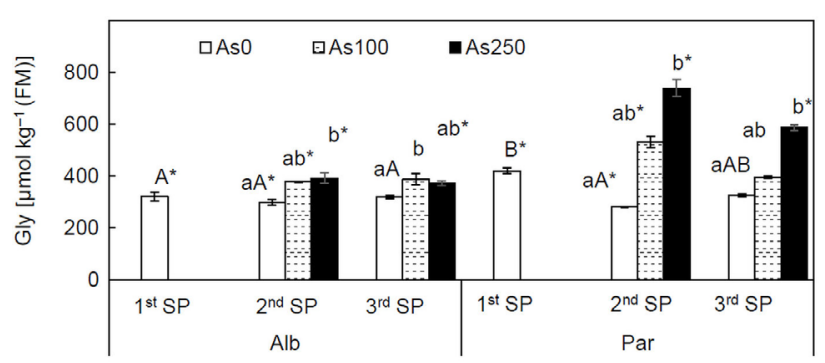

Fig. 4. Effect of As treatments on free glycine (Gly) content of Pteris cretica 'Albo-lineata' (Alb) and 'Parkerii' (Par) during the experiment. Data are means \pm standard deviation $(n=3)$. Different letters indicate significant differences $(p \leq 0.05)$ according to the Kruskal-Wallis's test (1) between treatments in each sampling period of fern (lowercase letter) and (2) between sampling period of control fronds of each fern (uppercase letter). * - significant differences $(p \leq 0.05)$ between ferns of individual treatment and sampling period according to the Kruskal-Wallis's test. As0 treatment without As supplementation; As100 - treatment with As dose of $100 \mathrm{mg} \mathrm{kg}^{-1}$; As 250 - treatment with As dose of $250 \mathrm{mg} \mathrm{kg}^{-1} ; \mathrm{FM}$ - fresh mass.

et al. 2020, Zemanová et al. 2020a,b), however, limited attention has been paid to As tolerance response to plant phenological growth stage variations (Yang et al. 2020). In the present study, the As accumulation in fronds of $P$. cretica Alb and Par was determined by the dose in the soil and duration of exposure (Table 1). Significant differences between these ferns were obtained and values of Alb confirmed the capacity for the As hyperaccumulation. Similar results were shown in our previous studies (Pavlíková et al. 2020, Zemanová et al. 2020a,b).

Although Li et al. (2007) indicated that As at low concentrations generally stimulated growth, As is considered phytotoxic and expected to affect negatively plant growth (Zhao et al.2010). Our results showed a reduction of frond biomass by As doses but a significant effect of As was confirmed only for Par in the $3^{\text {rd }}$ SP (Table 1). Also at this $\mathrm{SP}$, necrosis was observed on frond blades. Similar to our previous studies (Pavlíková et al. 2020, Zemanová et al. 2020b), results of Par ferns indicated a higher sensitivity to As doses in comparison to Alb ferns.

In plants, photosynthesis is important for plant growth and crucial for biomass gain (Soltan and Rashed 2003, Singh et al. 2019, Allakhverdiev 2020). Under As treatment, photosynthesis is reduced (Kofroňová et al. 2018) and a decrease in photosynthesis due to As is attributed to stomatal and nonstomatal limitations (Asgher et al. 2021). According to these authors, plants exhibit a decrease in Chl and PSII activity and stomatal conductance under As treatment. Although, several studies reported the effect of As on the number of photosynthetic parameters in ferns (Singh et al. 2006, Wang et al. 2012, Pavlíková et al. 2020), only limited information is available regarding species and/or cultivar-specific differences in photosynthesis. Therefore, we selected two cultivars of Pteris cretica for the study presented here. The values of $P$. cretica Alb photosynthetic parameters $\left(P_{\mathrm{N}}, E, g_{\mathrm{s}}\right)$ and
$\mathrm{F}_{\mathrm{v}} / \mathrm{F}_{\mathrm{m}}$ were significantly different than that of $P$. cretica Par. However, in response to As stress, studied ferns showed similar trends of these parameters (Fig. 1). In general, Alb and Par fronds exhibited reduced $P_{\mathrm{N}}, E, g_{\mathrm{s}}$, and $\mathrm{F}_{\mathrm{v}} / \mathrm{F}_{\mathrm{m}}$ with some exceptions.

$P_{\mathrm{N}}$ is the most representative photosynthetic characteristic of plants and its values directly reflect photosynthetic capacity (Sicher and Bunce 2001). In our study, the $P_{\mathrm{N}}$ of Alb and Par ferns decreased by As dose in the soil (Fig. 1A). Similar results were observed for P. cretica Alb and Par, as well as for As-nonhyperaccumulator P. straminea (Pavlíková et al. 2020). Conversely, the significant influence of SP was shown only for Par ferns, when the $P_{\mathrm{N}}$ of control variants increased with growth. Studies of As stress in plants have shown that the reduction in $P_{\mathrm{N}}$ is one of the most damaging effects of this metalloid, which could occur due to the decrease in photosynthetic pigments, interfered electron transport, and/or affected $g_{\mathrm{s}}$ (Gusman et al. 2013, Farooq et al. 2015, MeneguelliSouza et al. 2016).

In plants, a higher $g_{\mathrm{s}}$ has been associated with high $P_{\mathrm{N}}$ and this could be a strategy to increase tolerance against As stress (Singh et al. 2019). However, our results showed the decrease of $g_{\mathrm{s}}$ by the As dose in soil for studied ferns, except the Alb As100 variant of the $2^{\text {nd }}$ SP (Fig. 1C). At this treatment, $g_{\mathrm{s}}$ increased with the As dose in the soil. The effect of SP was very variable. According to Srivastava et al. (2013), who observed similar results under As treatments in Hydrilla verticillata, the initial increase of $g_{\mathrm{s}}$ is important to maintain photosynthesis under As stress. In other plants, the reduction of $g_{s}$ was determined (Gusman et al. 2013, Meneguelli-Souza et al. 2016, Anjum et al. 2017). Generally, in photosynthesis, a decrease of $g_{\mathrm{s}}$ can be caused by a decrease of $E$ and leads to a significant decrease in transpiration, which can slow down the absorption and transportation of water and nutrients (Gao et al. 2016). The $E$ values presented here showed a different response to As dose in the soil and SP between studied ferns (Fig. 1D). The trend of $E$ values was similar to that of $g_{\mathrm{s}}$ values in response to As treatments and SP, except for Par ferns in the $3^{\text {rd }}$ SP. This exception showed increased $E$ by the As doses in the soil compared to the control. Similar results observed Singh et al. (2019) for the As-tolerant genotype of Ricinus communis, which showed a lesser As accumulation in leaves than that of the studied Par ferns. A study with $P$. cretica Alb demonstrated the decrease of $E$ by As treatments in old fronds, while it increased in the young fronds (Zemanová et al. 2020a).

$\mathrm{F}_{\mathrm{v}} / \mathrm{F}_{\mathrm{m}}$ is an important parameter in plants responding to the external environment, used in studying the photosynthetic system, and is effective in monitoring the onset and development of stress (Ralph and Burchett 1998, Buschmann 2007, Yang et al. 2016). In general, the decrease of $F_{v} / F_{m}$ below 0.8 suggests the plant's response to stress (Yang et al. 2016). According to Nesterenko et al. (2006), $\mathrm{F}_{\mathrm{v}} / \mathrm{F}_{\mathrm{m}}$ ratio as well as $P_{\mathrm{N}}$ decreased in the process strengthening of the effect and after-effect of the stressful factor. Our results indicate that this phenomenon occurred during the As treatments of Alb and Par ferns (Fig. 1B). Similar results were shown for P. cretica Alb 
and Par (Pavlíková et al. 2020, Zemanová et al. 2020a), as well as for another As-hyperaccumulator $-P$. vittata (Wang et al. 2012). The significant influence of SP on $\mathrm{F}_{\mathrm{v}} / \mathrm{F}_{\mathrm{m}}$ of $P$. cretica Alb was in accordance with that of Wang et al. (2012), who reported that $\mathrm{F}_{\mathrm{v}} / \mathrm{F}_{\mathrm{m}}$ of P. cretica var. nervosa decreased over time, while it was unaffected by As treatment in this As-hyperaccumulator. These authors suggest that a different response of $F_{v} / F_{m}$ to As stress may be exhibited by different species of As-hyperaccumulators.

Photosynthetic pigments are the targets of oxidative stress, as well as toxic As effects, because they are some of the most important internal factors and/or biomarkers that can determine the capacity for photosynthesis (Ashraf and Harris 2013, Karimi et al. 2013). The content of photosynthetic pigments is an important index for the evaluation of As-tolerant plants (Karimi et al. 2013). Uptake of As leads to concentration-dependent losses of Chl and carotenoid pigments (Wang et al. 2012). In our study, the results of Alb ferns demonstrated a negligible variation in the $\mathrm{Chl}_{\mathrm{T}}$ and Car under As treatments, except the higher As dose in the soil in the $3^{\text {rd }}$ SP, while an increase with SP in control variants was observed (Fig. 2). In Par ferns, these photosynthetic pigments decreased by As doses in the soil, especially by the highest As dose (As250). Compared to Alb ferns, the content of $\mathrm{Chl}_{\mathrm{T}}$ and Car decreased with SP. Zemanová et al. (2020a) determined a decrease of $\mathrm{Chl}_{\mathrm{T}}$ content by As treatments in young and old fronds of $P$. cretica Alb, while the content of Car was unaffected by As stress. Stoeva and Bineva (2003) and Azizur Rahman et al. (2007) showed a decrease in $\mathrm{Chl}_{\mathrm{T}}$ and Car contents in As-nonhyperaccumulators. Additionally, Srivastava et al. (2013) observed a decrease in the content of these pigments in Hydrilla verticillata, a potential As-accumulator. According to them, the decrease of $\mathrm{Chl}_{\mathrm{T}}$ and Car contents may be only partly responsible for the As-induced decline in $P_{\mathrm{N}}$. However, Srivastava et al. (2017) stated that the decrease of pigment synthesis in plants is an indication of the lack of adaptive adjustments of pigment synthesis to high As concentrations, probably because of toxic As effects on plants.

Molecules of $\mathrm{Chl}$ contain $\mathrm{Mg}$ as a central element. This element is the activator of metalloenzymes and plays key roles in various physiological and biochemical processes, including stability and function of Chls in the photosynthesis (Ye et al. 2019). Metal/metalloid-stressed plants can substitute their $\mathrm{Mg}$-ion in Chl with available risk elements, e.g., $\mathrm{Cd}, \mathrm{Cu}, \mathrm{Ni}, \mathrm{Zn}$, and $\mathrm{Pb}$, which leads to the damage of photosynthetic activity and decay of Chl (Küpper et al. 1996, 1998). Mg together with K critically contribute to the process of photosynthesis and the subsequent long-distance transport of photoassimilates (Tränkner et al. 2018). Additionally, $\mathrm{K}$ is used as a plant protector against most abiotic stresses, including metal/metalloid toxicity (Hasanuzzaman et al. 2018). In our study, the content of $\mathrm{Mg}$ and $\mathrm{K}$ showed differences between Alb and Par ferns (Fig. 3). Lower contents of Mg and $\mathrm{K}$ were found in Par ferns compared to those in Alb ferns. However, compared to control variants, $\mathrm{Mg}$ and $\mathrm{K}$ contents at different As treatments were altered to a small extent in the studied ferns. A significant difference was observed in comparison between individual As doses in the soil. The effect of SP was clear only for the Mg content in Par ferns. In general, these results indicate that Par ferns are more sensitive to As toxicity than Alb ferns. Similar results of $\mathrm{Mg}$ content, elevated by high As doses, have been observed in old fronds of As-hyperaccumulators P. cretica Alb (Zemanová et al. 2020a) and P. vittata (Tu and Ma 2005), as well as in As-nonhyperaccumulators (Liu et al. 2007), suggesting that the high $\mathrm{Mg}$ content could be used by plants to counteract As toxicity. Shaibur et al. (2016) showed the increase of $\mathrm{Mg}$ content by As in Oryza sativa, while $\mathrm{K}$ content remained unchanged. Other authors determined the decrease of $\mathrm{K}$ content by As treatment in As-hyperaccumulators $P$. cretica and P. umbrosia (Saffari et al. 2009), as well as the increase of $\mathrm{K}$ content by As treatment in As-hyperaccumulator P. vittata (Tu and Ma 2005) and As-nonhyperaccumulator (Liu et al. 2007).

In plants, Gly is an essential amino acid for the biosynthesis of cytokinins, which can delay senescence via increased Chl biosynthesis (Pavlíková et al. 2020). This amino acid is found in Gly-rich proteins that are important for the growth and function of cell walls (Ringli et al. 2001). Furthermore, Gly from photorespiratory metabolism is a source for glutathione, a major antioxidant in plant cells (Mullineaux and Rausch 2005, Sunil et al. 2019), which plays a role in As tolerance (Tripathi et al. 2013). Mullineaux and Rausch (2005) stated that the linkage of glutathione, as a major cellular redox determinant to photosynthetic activity might be mean that can influenced the activity of redox sensitive signalling pathways. Gly, as an intermediate metabolite of the photorespiratory pathway could restrain photorespiration by feedback inhibition (Kang et al. 2018). In leaves, Gly content is generally considered to be a sensitive indicator for alterations in photorespiratory carbon flow (Eisenhut et al. 2007) and is used as a stress responsive amino acid (Dave et al. 2013). In our study, a higher content of Gly was determined in Par ferns compared to Alb ferns (Fig. 4). In Par ferns, an increase of Gly by As250 treatment was observed during growth, while Gly contents were lower in the $3^{\text {rd }} \mathrm{SP}$ than that in the $2^{\text {nd }} \mathrm{SP}$ of As variants of these ferns. In Alb ferns, the increase of Gly by As250 treatment only occurred in the $2^{\text {nd }}$ SP, and the effect of SP was not determined. An increase by As treatment was also found in P. cretica Alb and Par (Zemanová et al. 2020b), as well as in another As-hyperaccumulator Pityrogramma calomelanos (Campos et al. 2016). The increase of Gly by As suggests an increase in the photorespiration pathway, reducing the As toxic effect in photosystems (Campos et al. 2016). Our results for Alb and Par ferns were not in accordance with the results of Dave et al. (2013), who showed differences in Gly response to As stress between contrasting genotypes of rice. According to these authors, the high As-accumulating genotype had higher Gly contents than the low As-accumulating genotype.

Conclusions: In this experiment, all determined parameters reflected the difference between studied ferns in response to As stress during growth. To further verify their 
sensitivity to As, several photosynthetic and physiological parameters of the two cultivars under 100 and $250 \mathrm{mg} \mathrm{kg}^{-1}$ As doses were compared. The higher As accumulation was shown in Alb, where frond biomass was also higher than that of Par. In ferns, with increasing As doses, there was some inhibition of photosynthesis related to the decrease in $P_{\mathrm{N}}$ caused by changes in $g_{\mathrm{s}}, E$, and $\mathrm{F}_{\mathrm{v}} / \mathrm{F}_{\mathrm{m}}$. During growth, the results of $g_{\mathrm{s}}$ and $E$ had a similar trend, except the $3^{\text {rd }}$ sampling period of Par, when an increase of $E$ by As doses was observed. The effect of age in control variants was significant for the $\mathrm{Mg}$ content of Par, which decreased. Similarly, the growing period affected the content of $\mathrm{Chl}_{\mathrm{T}}$ and Car in fronds of Alb (increase) and Par (decrease). However, these photosynthetic pigments decreased by As doses in both ferns. Additionally, the content of stress-responsive amino acid, free Gly, showed differences between ferns; free Gly was significantly higher in Par than that in Alb and increased by As doses in this fern. Changes in measured photosynthetic and other physiological parameters in studied ferns suggested that $P$. cretica Par had a higher disruption of photosynthesis under As stress than $P$. cretica Alb, which was less sensitive to As.

\section{References}

Abbas G., Murtaza B., Bibi I. et al.: Arsenic uptake, toxicity, detoxification, and speciation in plants: physiological, biochemical, and molecular aspects. - Int. J. Environ. Res. Public Health 15: 59, 2018.

Ahsan N., Lee D.-G., Alam L. et al.: Comparative proteomic study of arsenic-induced differentially expressed proteins in rice roots reveals glutathione plays a central role during As stress. - Proteomics 8: 3561-3576, 2008.

Allakhverdiev S.I.: Optimising photosynthesis for environmental fitness. - Funct. Plant Biol. 47: III-VII, 2020.

Anjum S.A., Tanveer M., Hussain S. et al.: Alteration in growth, leaf gas exchange, and photosynthetic pigments of maize plants under combined cadmium and arsenic stress. - Water Air Soil Poll. 228: 13, 2017.

Asgher M., Ahmed S., Sehar Z. et al:: Hydrogen peroxide modulates activity and expression of antioxidant enzymes and protects photosynthetic activity from arsenic damage in rice (Oryza sativa L.). - J. Hazard. Mater. 401: 123365, 2021.

Ashraf M., Harris P.J.C.: Photosynthesis under stressful environments: An overview. - Photosynthetica 51: 163-190, 2013.

Azizur Rahman M., Hasegawa H., Mahfuzur Rahman M. et al.: Effect of arsenic on photosynthesis, growth and yield of five widely cultivated rice (Oryza sativa L.) varieties in Bangladesh. - Chemosphere 67: 1072-1079, 2007.

Buschmann C.: Variability and application of the chlorophyll fluorescence emission ratio red/far-red of leaves. - Photosynth. Res. 92: 261-271, 2007.

Campos N.V., Araújo T.O., Arcanjo-Silva S. et al.: Arsenic hyperaccumulation induces metabolic reprogramming in Pityrogramma calomelanos to reduce oxidative stress. Physiol. Plantarum 157: 135-146, 2016.

Claveria R.J.R., Perez T.R., Apuan M.J.B. et al.: Pteris melanocaulon Fée is an As hyperaccumulator. - Chemosphere 236: 124380, 2019.

Dave R., Tripathi R.D., Dwivedi S. et al.: Arsenate and arsenite exposure modulate antioxidants and amino acids in contrasting arsenic accumulating rice (Oryza sativa L.) genotypes. -
J. Hazard. Mater. 262: 1123-1131, 2013.

Eisenhut M., Bauwe H., Hagemann M.: Glycine accumulation is toxic for the cyanobacterium Synechocystis sp. strain PCC 6803 , but can be compensated by supplementation with magnesium ions. - FEMS Microbiol. Lett. 277: 232-237, 2007.

Eze V.C., Harvey A.P.: Extractive recovery and valorisation of arsenic from contaminated soil through phytoremediation using Pteris cretica. - Chemosphere 208: 484-492, 2018.

Farooq M.A., Li L., Ali B. et al.: Oxidative injury and antioxidant enzymes regulation in arsenic-exposed seedlings of four Brassica napus L. cultivars. - Environ. Sci. Pollut. R. 22: 10699-10712, 2015.

Fayiga A.O., Ma L.Q.: Arsenic uptake by two hyperaccumulator ferns from four arsenic contaminated soils. - Water Air Soil Poll. 168: 71-89, 2005.

Gago J., Coopman R.E., Cabrera H.M. et al.: Photosynthesis limitations in three fern species. - Physiol. Plantarum 149: 599-611, 2013.

Gao M., Qi Y., Song W., Xu H.: Effects of di-n-butyl phthalate and di (2-ethylhexyl) phthalate on the growth, photosynthesis, and chlorophyll fluorescence of wheat seedlings. - Chemosphere 151: 76-83, 2016.

Gusman G.S., Oliveira J.A., Farnese F.S., Cambraia J.: Arsenate and arsenite: the toxic effects on photosynthesis and growth of lettuce plants. - Acta Physiol. Plant. 35: 1201-1209, 2013.

Hasanuzzaman M., Borhannuddin Bhuyan M.H.M., Nahar K. et al:: Potassium: A vital regulator of plant responses and tolerance to abiotic stresses. - Agronomy-Basel 8: 31, 2018.

Kang T., Wu H.D., Lu B.Y. et al.: Low concentrations of glycine inhibit photorespiration and enhance the net rate of photosynthesis in Caragana korshinskii. - Photosynthetica 56: 512-519, 2018.

Karimi N., Siyahat Shayesteh L., Ghasmpour H., Alavi M.: Effects of arsenic on growth, photosynthetic activity, and accumulation in two new hyperaccumulating populations of Isatis cappadocica Desv. - J. Plant Growth Regul. 32: 823-830, 2013.

Kofroňová M., Mašková P., Lipavská H.: Two facets of world arsenic problem solution: crop poisoning restriction and enforcement of phytoremediation. - Planta 248: 19-35, 2018.

Küpper H., Küpper F., Spiller M.: Environmental relevance of heavy metal-substituted chlorophylls using the example of water plants. - J. Exp. Bot. 47: 259-266, 1996.

Küpper H., Küpper F., Spiller M.: In situ detection of heavy metal substituted chlorophylls in water plants. - Photosynth. Res. 58: 123-133, 1998.

Li C.X., Feng S.L., Shao Y. et al.: Effects of arsenic on seed germination and physiological activities of wheat seedlings. J. Environ. Sci. 19: 725-732, 2007.

Liu W., Fu Y., Hu G. et al.: Identification and fine mapping of a thermo-sensitive chlorophyll deficient mutant in rice (Oryza sativa L.). - Planta 226: 785-795, 2007.

Luongo T., Ma L.Q.: Characteristics of arsenic accumulation by Pteris and non-Pteris ferns. - Plant Soil 277: 117, 2005.

Meharg A.A.: Variation in arsenic accumulation-hyperaccumulation in ferns and their allies. - New Phytol. 157: 25-31, 2003.

Meharg A.A., Hartley-Whitaker J.: Arsenic uptake and metabolism in arsenic resistant and nonresistant plant species. New Phytol. 154: 29-43, 2002.

Meneguelli-Souza A.C., Vitória A.P., Vieira T.O. et al.: Ecophysiological responses of Eichhornia crassipes (Mart.) Solms to $\mathrm{As}^{5+}$ under different stress. - Photosynthetica 54: 243-250, 2016.

Mullineaux P.M., Rausch T.: Glutathione, photosynthesis and 
the redox regulation of stress-responsive gene expression. Photosynth. Res. 86: 459-474, 2005.

Nesterenko T.V., Tikhomirov A.A., Shikhov V.N.: Ontogenetic approach to the assessment of plant resistance to prolonged stress using chlorophyll fluorescence induction method. Photosynthetica 44: 321-332, 2006.

Nishida K., Kodama N., Yonemura S. et al.: Rapid response of leaf photosynthesis in two fern species Pteridium aquilinum and Thelypteris dentata to changes in $\mathrm{CO}_{2}$ measured by tunable diode laser absorption spectroscopy. - J. Plant Res. 128: 777-789, 2015.

Paoli L., Landi M.: The photosynthetic performance of sterile and fertile sporophytes in a natural population of the fern Dryopteris affinis. - Photosynthetica 51: 312-316, 2013.

Pavlíková D., Zemanová V., Pavlík M. et al.: Response of cytokinins and nitrogen metabolism in the fronds of Pteris sp. under arsenic stress. - PLoS ONE 15: e0233055, 2020.

Ralph P.J., Burchett M.D.: Photosynthetic response of Halophila ovalis to heavy metal stress. - Environ. Pollut. 103: 91-101, 1998.

Ringli C., Keller B., Ryser U.: Glycine-rich proteins as structural components of plant cell walls. - Cell Mol. Life Sci. 58: 14301441, 2001.

Saffari M., Fathi H., Emadi M. et al.: Uptake, translocation, and transformation of arsenic by four fern species in arsenicspiked soils. - Commun. Soil Sci. Plant Anal. 40: 3420-3434, 2009.

Shaibur M.R., Sera K., Kawai S.: Effect of arsenic on concentrations and translocations of mineral elements in the xylem of rice. - J. Plant Nutr. 39: 365-376, 2016.

Sicher R.C., Bunce J.A.: Adjustments of net photosynthesis in Solanum tuberosum in response to reciprocal changes in ambient and elevated growth $\mathrm{CO}_{2}$ partial pressures. - Physiol. Plantarum 112: 55-61, 2001.

Singh N., Ma L.Q., Srivastava M., Rathinasabapathi B.: Metabolic adaptation to arsenic-induced oxidative stress in Pteris vittata L. and Pteris ensiformis L. - Plant Sci. 170: 274-282, 2006.

Singh R., Jha A.B., Misra A.N., Sharma P.: Differential responses of growth, photosynthesis, oxidative stress, metals accumulation and NRAMP genes in contrasting Ricinus communis genotypes under arsenic stress. - Environ. Sci. Pollut. R. 26: 31166-31177, 2019.

Skoczowski A., Rut G., Oliwa J., Kornas A.: Sporulation modifies the photosynthetic activity of sporotrophophyll leaves of Platycerium bifurcatum. - Photosynthetica 58: 488-496, 2020.

Soltan M.E., Rashed M.N.: Laboratory study on the survival of water hyacinth under several conditions of heavy metal concentrations. - Adv. Environ. Res. 7: 321-334, 2003.

Srivastava S., Sinha P., Sharma Y.K.: Status of photosynthetic pigments, lipid peroxidation and anti-oxidative enzymes in Vigna mungo in presence of arsenic. - J. Plant Nutr. 40: 298-306, 2017.

Srivastava S., Srivastava A.K., Singh B. et al.: The effect of arsenic on pigment composition and photosynthesis in Hydrilla verticillata. - Biol. Plantarum 57: 385-389, 2013.

Stoeva N., Bineva T.: Oxidative changes and photosynthesis in oat plants grown in As-contaminated soil. - Bulg. J. Plant
Physiol. 29: 87-95, 2003

Sunil B., Saini D., Bapatla R.B. et al.: Photorespiration is complemented by cyclic electron flow and the alternative oxidase pathway to optimize photosynthesis and protect against abiotic stress. - Photosynth. Res. 139: 67-79, 2019.

Tränkner M., Tavakol E., Jákli B.: Functioning of potassium and magnesium in photosynthesis, photosynthate translocation and photoprotection. - Physiol. Plantarum 163: 414-431, 2018.

Tripathi P., Tripathi R.D., Singh R.P. et al.: Arsenite tolerance in rice (Oryza sativa L.) involves coordinated role of metabolic pathways of thiols and amino acids. - Environ. Sci. Pollut. R. 20: 884-896, 2013.

Tu C., Ma L.Q.: Effects of arsenic on concentration and distribution of nutrients in the fronds of the arsenic hyperaccumulator Pteris vittata L. - Environ. Pollut. 135: 333-340, 2005.

Tu C., Ma L.Q., Bondada B.: Arsenic accumulation in the hyperaccumulator Chinese Brake (Pteris vittata L.) and its utilization potential for phytoremediation. - J. Environ. Qual. 31: 1671-1675, 2002.

Volkova L., Tausz M., Bennett L.T., Dreyer E.: Interactive effects of high irradiance and moderate heat on photosynthesis, pigments, and tocopherol in the tree-fern Dicksonia antarctica. - Funct. Plant Biol. 36: 1046-1056, 2009.

Wan X.M., Lei M., Chen T.B. et al.: Role of transpiration in arsenic accumulation of hyperaccumulator Pteris vittata L. Environ. Sci. Pollut. R. 22: 16631-16639, 2015.

Wang H.B., Wong M.H., Lan C.Y. et al.: Uptake and accumulation of arsenic by 11 Pteris taxa from southern China. - Environ. Pollut. 145: 225-233, 2007.

Wang H.B., Xie F., Yao Y.Z. et al.: The effects of arsenic and induced-phytoextraction methods on photosynthesis in Pteris species with different arsenic-accumulating abilities. Environ. Exp. Bot. 75: 298-306, 2012.

Wang Y., Chai L., Yang Z. et al:: Chlorophyll fluorescence in leaves of Ficus tikoua under arsenic stress. - B. Environ. Contam. Tox. 97: 576-581, 2016.

Yang G.Y., Zhong H., Liu X. et al:: Arsenic distribution, accumulation and tolerance mechanisms of Typha angustifolia in different phenological growth stages. - B. Environ. Contam. Tox. 104: 358-365, 2020.

Yang N., Wang X., Cotrozzi L. et al.: Ozone effects on photosynthesis of ornamental species suitable for urban green spaces of China. - Urban For. Urban Gree. 20: 437-447, 2016.

Ye X., Chen X.F., Deng C.L. et al.: Magnesium-deficiency effects on pigments, photosynthesis and photosynthetic electron transport of leaves, and nutrients of leaf blades and veins in Citrus sinensis seedlings. - Plants-Basel 8: 389, 2019.

Zemanová V., Pavlíková D., Pavlík M.: Free amino acid regulation in fronds and roots of two Pteris cretica $\mathrm{L}$. ferns under arsenic stress. - Plant Soil Environ. 66: 483-492, 2020b.

Zemanová V., Popov M., Pavlíková D. et al.: Effect of arsenic stress on 5-methylcytosine, photosynthetic parameters and nutrient content in arsenic hyperaccumulator Pteris cretica (L.) var. Albo-lineata. - BMC Plant Biol. 20: 130, 2020a.

Zhao F.J., McGrath S.P., Meharg A.A.: Arsenic as a food chain contaminant: mechanisms of plant uptake and metabolism and mitigation strategies. - Annu. Rev. Plant Biol. 61: 535559,2010 .

(C) The authors. This is an open access article distributed under the terms of the Creative Commons BY-NC-ND Licence. 